\section{Ultrasound-guided drug delivery in cancer}

\author{
Sayan Mullick Chowdhury, Taehwa Lee, Jürgen K. Willmann \\ Department of Radiology, Stanford University School of Medicine, Stanford, CA, USA
}

Recent advancements in ultrasound and microbubble (USMB) mediated drug delivery technology has shown that this approach can improve spatially confined delivery of drugs and genes to target tissues while reducing systemic dose and toxicity. The mechanism behind enhanced delivery of therapeutics is sonoporation, the formation of openings in the vasculature, induced by ultrasound-triggered oscillations and destruction of microbubbles. In this review, progress and challenges of USMB mediated drug delivery are summarized, with special focus on cancer therapy.

Keywords: Ultrasonography; Drug delivery systems; Cancer therapy; Genetic therapy; Microbubbles

\section{Introduction}

In addition to diagnostic purposes, ultrasound is increasingly being used for therapeutic applications including imaging-guided drug and gene delivery to various tissue types [1-3]. Ultrasound-guided delivery of therapeutics has gained special attention since it allows spatially confined delivery of drugs into a target areas, such as a tumor, while minimizing systemic dose and toxicity $[4,5]$. Since ultrasound is widely available, relatively inexpensive and portable, along with the ability to focus it onto a target area non-invasively with high precision, ultrasound-guided drug delivery is a promising approach to efficiently treat certain cancer types that are anatomically accessible for ultrasound (for example liver tumors) $[4,5]$.

Through a process called sonoporation, ultrasound and microbubble (USMB) mediated cavitation generates transient or permanent pores in the walls of blood vessels and can significantly enhance extravascular delivery of therapeutics in the region of interest (Fig. 1) [6]. USMB mediated drug delivery can be triggered through both stable and inertial cavitation of microbubbles. Cavitation is defined as the growing and shrinking response of microbubbles when subjected to the alternating low and high-pressure portions of the ultrasound wave [7]. Stable cavitation occurs when microbubbles stably oscillate without collapsing in an acoustic field (Fig. 2). In contrast, when microbubbles violently grow and collapse, this process is called inertial cavitation (Fig. 2). While both stable and inertial cavitation exert mechanical forces on adjacent tissues, microbubble collapse (inertial cavitation) can result in additional secondary mechanical effects such as shockwaves and liquid jetting that further enhance the effects of sonoporation.

USMB mediated drug delivery is considered safe as cell membrane permeabilizations caused by acoustic cavitation are considered reversible and cell membranes usually return to their original conformation within seconds [8]. This allows delivery of therapeutics without compromising physiological barriers and defense mechanisms of the tissue [8]. From a clinical standpoint, this

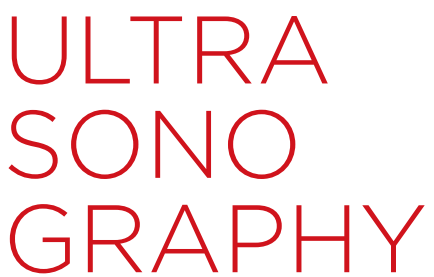

REVIEW ARTICLE

https://doi.org/10.14366/usg. 17021 pISSN: 2288-5919 • eISSN: 2288-5943

Ultrasonography 2017;36:171-184

Received: March 1, 2017

Revised: April 23, 2017

Accepted: May 1, 2017

Correspondence to: Jürgen K. Willmann, MD, Department of Radiology, Stanford University School of Medicine, 300 Pasteur Drive, Room H1307, Stanford, CA 943055621, USA

Tel. +1-650-725-1812

Fax. +1-650-723-1909

E-mail: willmann@stanford.edu

This is an Open Access article distributed under the terms of the Creative Commons Attribution NonCommercial License (http://creativecommons.org/ licenses/by-nc/3.0/) which permits unrestricted noncommercial use, distribution, and reproduction in any medium, provided the original work is properly cited.

Copyright (C) 2017 Korean Society of Ultrasound in Medicine (KSUM)

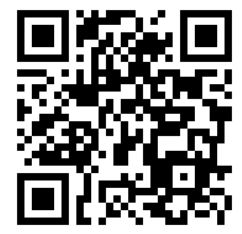

How to cite this article:

Chowdhury SM, Lee T, Willmann JK. Ultrasound-guided drug delivery in cancer. Ultrasonography. 2017 Jul;36(3):171-184. 
approach is attractive because the treatment is localized to only those areas ultrasound is applied to $[9,10]$. Moreover, therapeutic effects evoked through sonoporation have been observed for several days to weeks with prolonged therapeutic results [11]. Also, several microbubble formulations are already Food and Drug Administration (FDA) approved, others are undergoing clinical testing, which supports clinical translation of this therapeutic approach.

USMB mediated drug delivery has been tested using a variety of ultrasound parameters and towards the treatment of many diseases including cancer [12]. In this review, an overview on USMB mediated drug delivery in cancer, including the mechanisms of drug delivery, the current status of preclinical and clinical applications, and future work needed to facilitate clinical translation is presented.

\section{Microbubbles and Drug Carriers}

Both endogenous and exogenous microbubbles can be used for USMB mediated drug delivery $[13,14]$. Endogenous microbubbles are small gaseous pockets that are present naturally within tissues; these can be leveraged for sonoporation once certain cavitation thresholds are exceeded following ultrasound delivery (the threshold is directly proportional to the square root of the applied ultrasound frequency). Typically high acoustic pressures are required to take advantage of endogenous microbubbles. Endogenous microbubbles have been successfully utilized to deliver drugs into the gastrointestinal tract [15] as well as for trans-dermal drug delivery $[16,17]$, where both cavitation within and under the skin can cause enhanced drug delivery. However, there is only limited experience on leveraging endogenous microbubbles for cancer therapy [18].

Exogenous contrast microbubbles are externally administered and have a lower threshold for cavitation compared to endogenous microbubbles because they can concentrate ultrasound acoustic energy more efficiently. Collapse of these exogenous microbubbles releases energy at the tumor site, resulting in enhanced drug delivery and targeted treatment of tumors (Figs. 3, 4A) [19-22]. Since in the presence of exogenous microbubbles cavitation thresholds are greatly reduced, relatively low pressure amplitudes are required for sonoporation to take place. Currently, several FDA-approved microbubbles are commercially available in the United States (e.g., Optison, Definity, Lumanson) and used for diagnostic purposes in

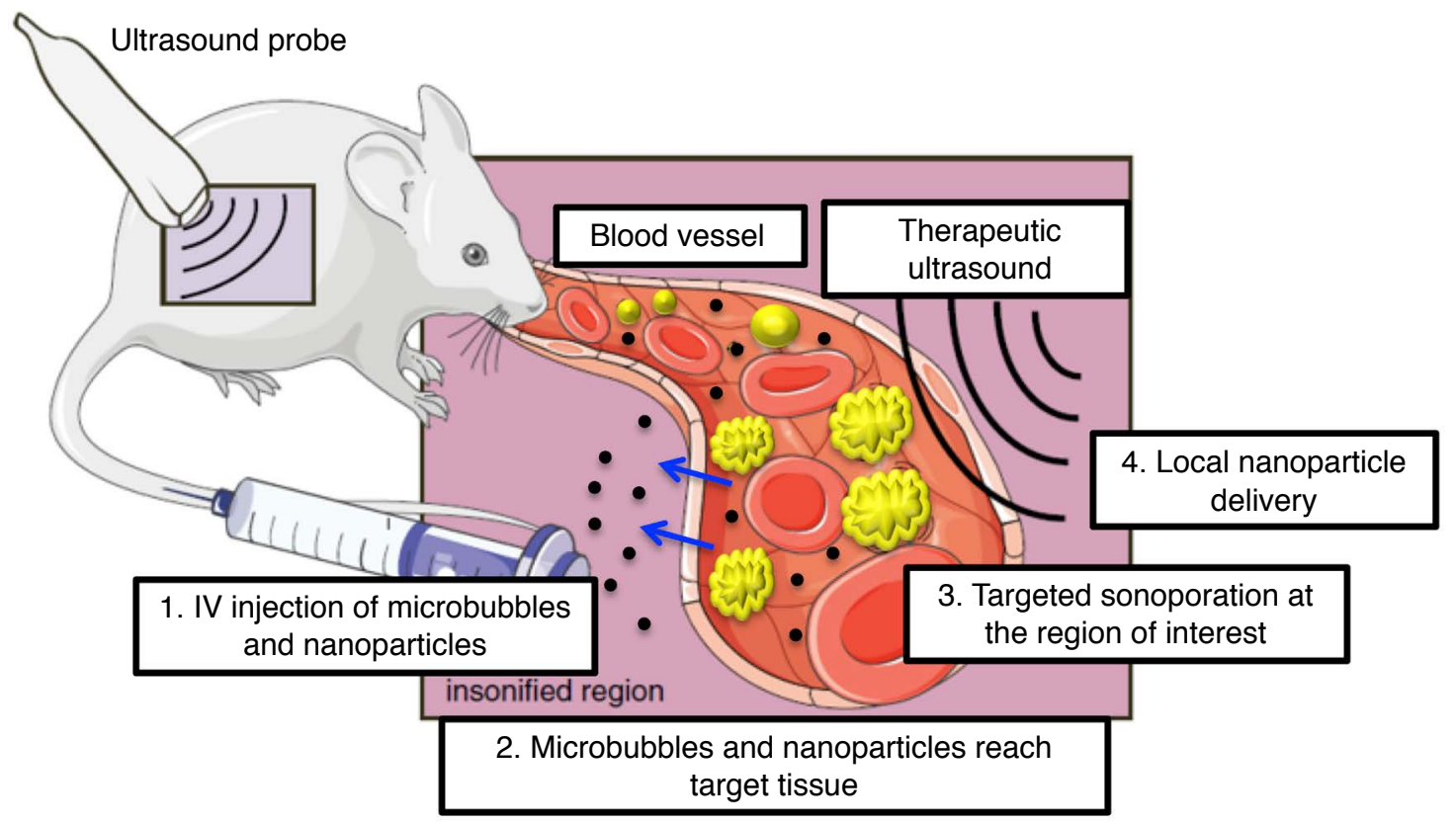

Microbubble

- Nanoparticle

Microbubble

undergoing inertial cavitation

Fig. 1. Principle of ultrasound and microbubble mediated nanoparticle delivery in vivo. Microbubbles and nanoparticles are injected intravenously (IV) and therapeutic ultrasound is focused at the region of interest to induce microbubble cavitation and subsequent opening of the vasculature to allow penetration of therapeutic payload in nanoparticles into the extravascular space. Modified from Delalande et al. Gene 2013;525:191-199, with permission from Elsevier through RightsLink [6]. 


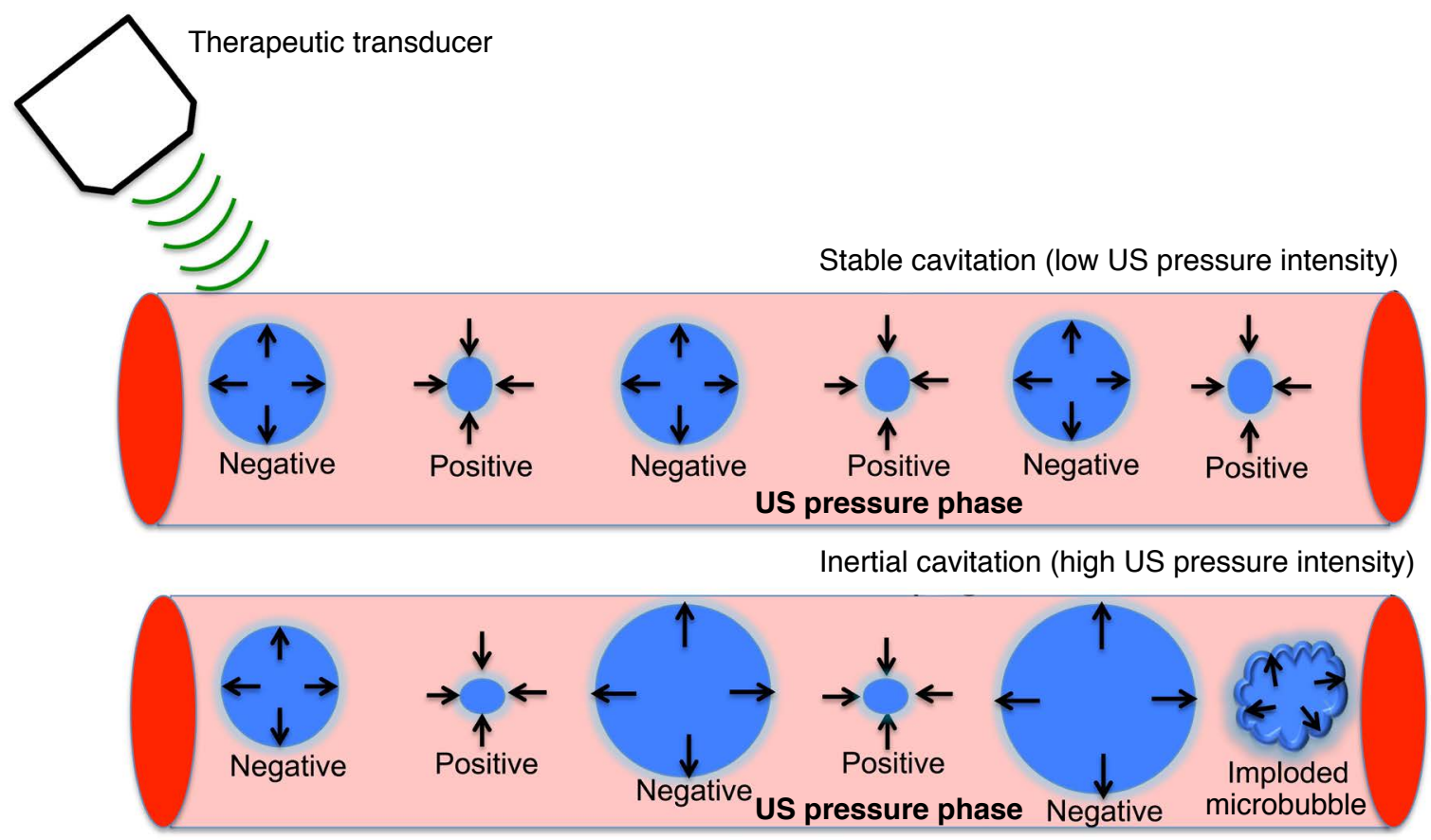

Fig. 2. Schematic drawing of the principles of stable and inertial cavitation. The type of cavitation strongly depends on pressure intensity. When relatively low pressure intensities are applied, the negative and positive pressure phases of the ultrasound (US) waves cause respective growth and shrinkage of microbubbles, which can repeat stably for many cycles. Such stable oscillation of microbubbles which depends on their resonance frequency, is known as stable cavitation. In contrast, when relatively high pressure intensities are applied, microbubbles violently grow to a much larger size followed by energetic collapse, a phenomenon known as inertial cavitation.

A

B

C

D

$\mathrm{E}$ $\mathrm{F}$

G

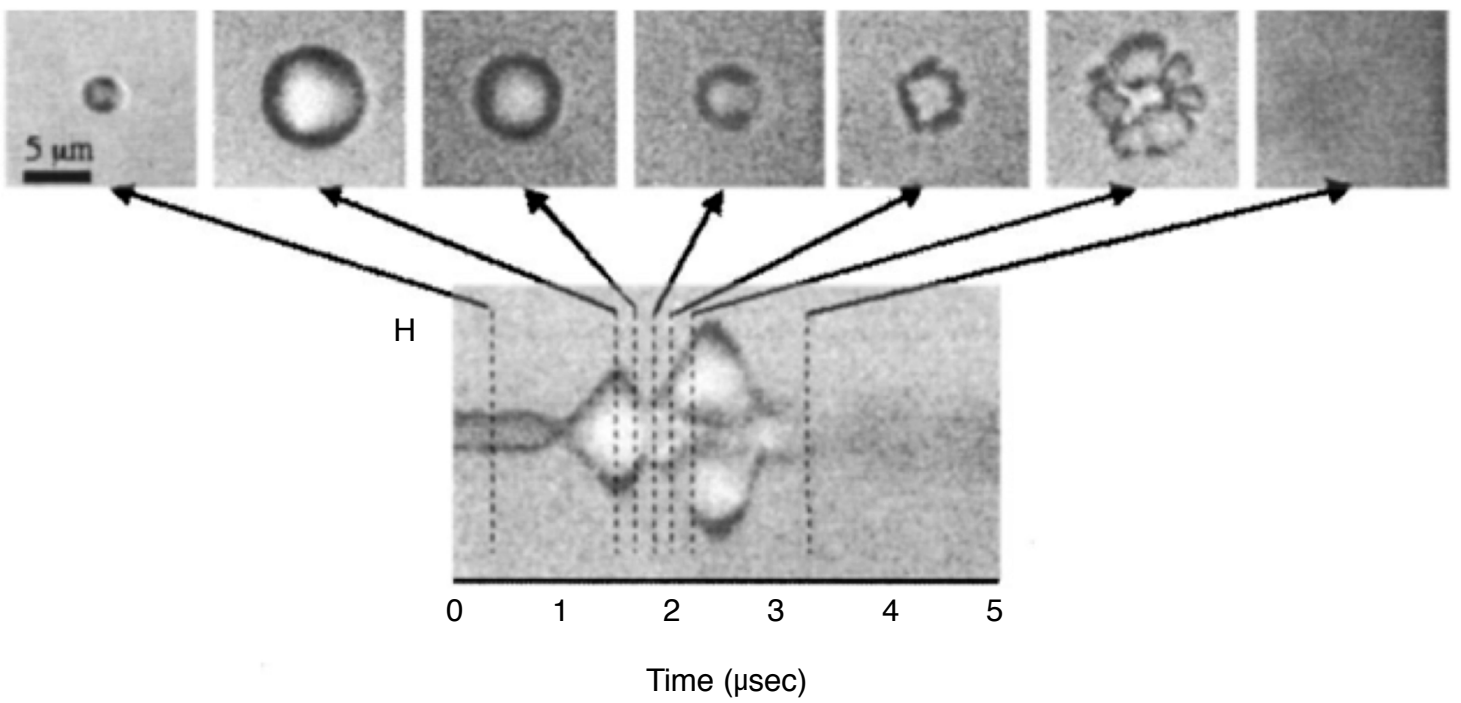

Fig. 3. Visualizing inertial cavitation.

Optical frame images $(A-G)$ and corresponding streak image $(H)$ shows oscillation and inertial cavitation of a microbubble over a 5 -microsecond period in response to ultrasound. Initially, the microbubble had a diameter of $\sim 3 \mu \mathrm{m}$. The microbubble then underwent expansion and contraction and finally fragmentation due to inertial cavitation. Optical data was captured with a combined frame and streak camera (Imacon 468, DRS Hadland). Modified from Chomas et al. Appl Phys Lett 2000;77:1056-1058, with permission from AIP Publishing through RightsLink [21]. 
the clinics $[18,23]$. These microbubbles comprise a gaseous core (e.g., perfluorocarbons) encapsulated by a shell, and range in size between 1-4 $\mu \mathrm{m}$, which is smaller than the size of red blood cells. This allows them to freely circulate within the vasculature. Due to their size of several micrometers, microbubbles are purely intravascular contrast agents.

Volatile liquid droplets stabilized as emulsions are currently being explored as an alternative to traditional exogenous microbubbles [24]. Exposed to ultrasound, these droplets undergo acoustic droplet vaporization to yield gas bubbles. Due to their smaller size, nanodroplets have the potential to leave the vascular compartment and penetrate into the extravascular cancer stroma tissue before transitioning into gas bubbles, which may further increase drug delivery efficacy [25].

The route of microbubble and drug administration as well as the type and dose of microbubbles may affect the efficiency of drug delivery and therapeutic effects. Several administration routes, which depend on the tumor type, location, and environment have been explored, including intratumoral, intraperitoneal, and intravenous injection of microbubbles. In general, intratumoral and intraperitoneal injections are well suitable to increase local microbubble and drug concentrations, but are invasive routes and only applicable for a few tumors (e.g., peritoneal metastases for intraperitoneal administration). Also, intratumoral injection may results in heterogeneous distribution of the payload, depending on the size and composition of the tumor. Intravenous administrations of microbubbles and drugs are therefore often preferred as difficultto-reach regions can also be treated well via this route. However, intravenous delivery results in higher systemic toxicity and some therapeutic agents (e.g., genes when injected directly into the blood) may be rapidly degraded in the circulation.

While drugs can be directly co-injected with microbubbles [26], several may benefit from encapsulation in a dedicated drug carrier (e.g., genes) to minimize rapid degradation in the blood circulation $[11,27]$. For this purpose, drugs can be either loaded into or onto microbubbles or into dedicated drug carriers $[28,29]$.

\section{Drug-Loaded Microbubbles}

In this approach, microbubbles are loaded with a certain drug during synthesis. As such, the amount of drug that can be delivered depends on the number of injected microbubbles and the amount of drug loaded into or onto each microbubble [30]. The amount of drug per microbubble can vary substantially depending on the type of drug being loaded, the type of microbubble and the loading strategy. Unger et al. [31] showed that 2.9- $\mu \mathrm{m}$-sized lipid microbubbles could be loaded with $\sim 1.5 \times 10^{-8} \mathrm{mg}$ of the anti-cancer drug paclitaxel per microbubble with a $100 \%$ loading efficiency $(15 \mathrm{mg} / \mathrm{mL}$ drug with
$10^{9}$ microbubbles $/ \mathrm{mL}$ ). In a similar study, Tartis et al. [32] showed a substantially lower loading efficiency (33\%) of paclitaxel into 1.4- $\mu \mathrm{m}$ lipid microbubbles.

Several loading strategies of microbubbles have been proposed, including loading/incorporating drugs into microbubbles or attaching them onto the microbubble shell through covalent or non-covalent interactions [30]. For example, it has been shown that negatively charged therapeutics (e.g., genetic material) can be loaded onto the shell of cationic microbubbles through electrostatic interactions $[28,29,33]$.

\section{Targeted Microbubbles}

Microbubbles can be molecularly targeted by adding binding ligands onto the shell that allow them to specifically accumulate at certain target area sites [34-41]. Typically, these microbubbles are targeted to molecules that are differentially expressed on the vasculature of certain diseases such as cancer [36-38,40-46]. Targeted microbubbles circulate in the blood stream, find their targets and bind specifically before ultrasound can trigger drug delivery $[7,47,48]$. This ensures highly specific delivery of drugs to sites where only attached microbubbles are present $[7,47-49]$. However, the success of this approach depends on the expression levels and homogeneous distribution of the targets in the treated tissue. Further studies are needed to assess whether there is a benefit of using targeted versus non-targeted microbubbles for USMB mediated drug delivery. Also, currently, there is only one clinical grade molecularly-targeted contrast agent (BR55; targeted at VEGFR2/KDR) in clinical development but not yet FDA approved $[36,50-52]$.

\section{Nanoparticles}

Drug loaded nanoparticles co-injected or attached to microbubbles have been explored as drug carriers in USMB mediated drug delivery in cancer (Fig. 1) $[53,54]$. Several types of nanoparticles have been used for this purpose including gold nanoparticles [55], silica nanoparticles [56], polymer nanoparticles [5], and liposomal formulations [57]. Combing microbubbles with nanoparticles have resulted in up to 34-fold increase in drug loading capacity compared to microbubbles alone $[42,58]$. In particular, use of biocompatible and biodegradable nanoparticles such as already FDA-approved poly lactic-co-glycolic acid (PLGA) nanoparticles are advantageous because, once they enter the extravascular compartment through the help of sonoporation, these nanoparticles are endocytosed rapidly by tumor cells where they can slowly release their cargo over several days to weeks, thereby providing a sustained therapeutic effect at the treatment site $[5,22,59,60]$. Using PLGA-nanoparticles, substantial amounts of therapeutic microRNAs (non-coding small RNAs that 
are emerging as promising drugs for cancer therapy by interfering with multiple signaling pathways) could be delivered into preclinical models of human colon cancer and hepatocellular carcinoma (HCC) with substantial therapeutic effects after a single treatment $[5,22]$.

\section{Microbubble Behavior during USMB Drug Delivery}

\section{Stable and Inertial Cavitation}

Although USMB mediated drug delivery has been shown to be highly effective in cell culture experiments, in in vivo conditions several physiological barriers have to be overcome that usually hinder injected drugs from reaching their target sites [4]. Specifically, drugs have to first extravasate across blood vessels and then travel through the extravascular compartment before reaching the target cells (e.g., cancer cells) which then need to incorporate them. To overcome these barriers, sufficiently high driving forces are required as diffusion and convection are insufficient as the only driving forces. USMB mediated cavitation cannot only create pathways via pore creation, but also provide therapeutic agents with sufficient momentum to travel within the target tissue. Stable as well as inertial cavitation can contribute towards USMB mediated drug delivery. In stable cavitation, microbubbles mechanically push on the walls of the blood vessels to increase the size of the gaps between the endothelial cells [61]. This allows drugs to enter the target tissue [61]. Moreover, stable cavitation has also been employed to shear open particles such as liposomal vesicles used in drug delivery. Inertial cavitation, in comparison, exerts more aggressive mechanical forces like jetting and shockwaves that result from collapse of the microbubbles [24]. As such, it is expected that higher amounts of drugs can enter tumor tissues through inertial cavitation.

\section{Microbubble Dynamics}

Microbubble dynamics with the direct environment play an important role in USMB mediated drug delivery. Subject to different environments, cavitation behaviors are substantially changed, which in turn drastically affects drug delivery outcomes. In fact, single microbubble dynamics in an isolated environment, while well studied, cannot be directly translated to multiple microbubbles that interact with each other and their surroundings in vivo. For example, it has been shown that the distance between two microbubbles as well as the distance between microbubbles and boundary can influence cavitation. Neighboring boundaries and microbubbles can restrict microbubble growth when they are sufficiently close, thus, reducing cavitation effects. It has been shown that microbubble cavitation (stable or inertial) in response to ultrasound exposure exerts forces on deformable tissue boundaries which in turn will affect microbubble behavior. Specifically, confined deformable environments such as microvessels affect microbubble interactions by (1) reducing expansion of microbubbles, (2) restricting fragmentation or jets during cavitation, and (3) deformation of vessel walls by with the deformation being directly proportional to size of the microbubbles $[62,63]$. When microbubbles are injected into blood vessels they interact with each other and these interactions can affect their cavitation, sonoporation, and drug delivery outcomes as well. It has also been found that decreasing inter-microbubble distance can increase the microbubble lifetime; however, increased microbubble lifetime is not directly proportional to improved drug delivery efficacy [64-66]. Arora et al. [67] showed that decreasing microbubble concentrations from 30 microbubbles $/ \mathrm{mL}$ to 3 microbubbles/mL decreased the maximum microbubble cluster size and increased cavitation lifetime of the cluster in vitro. Two or more growing microbubbles can also merge into a single microbubble under high-pressure ultrasound typically used during sonoporation $[63,68]$. Although cavitation of fused microbubbles can result in larger mechanical forces resulting in larger pore sizes, this may also cause more damage in the tissue. Static microbubble fusion, which is fusion of microbubbles in the absence of ultrasound, is also a factor that decreases microbubble circulation time. However, this issue has been largely addressed through PEGylation (i.e., addition of polyethylene glycol groups which prevents aggregation) of the microbubbles [69]. It has also been shown that low microbubble concentration reduces the chances of homogenous treatment of the diseased site while very high microbubble concentration can cause irreversible damages to tissue. In preclinical studies, typically $10^{7}-$ $10^{8}$ microbubbles are used per milliliter of injected dose.

\section{Ultrasound Parameters}

In addition to the type and concentration of microbubbles and drug carriers, the combination of certain ultrasound parameters including frequency, intensity, Mechanical Index (MI) and duration of ultrasound exposure can influence the efficacy of ultrasoundmediated drug delivery [22].

\section{Frequency}

The typical ultrasound frequency used for drug delivery ranges from $\mathrm{kHz}$ to $\mathrm{MHz}$ levels, depending on the tissue type and the model organism that had been used for preclinical evaluations. In general, for therapeutic applications, the ultrasound frequency is lower than that for diagnostic purposes [70]. A lower ultrasound frequency ensures deeper tissue penetration due to reduced attenuation leading to optimum therapeutic outcomes. The frequency of ultrasound used also depends on the type of microbubbles employed 
as the use of an ultrasound frequency close to or similar to resonant frequency of the microbubbles promotes stable microbubble cavitation $[71,72]$. However, in case of higher acoustic pressures causing inertial cavitation, the frequency used becomes a less important consideration because microbubbles collapse under the high acoustic pressure.

\section{Intensity}

Since high intensity ultrasound can potentially cause tissue alterations due to ultrasound associated heating effects, the FDA has regulated the intensity to one that causes less than a $1{ }^{\circ} \mathrm{C}$ rise in temperature $[73,74]$. Typically, ultrasound intensities used for delivery applications range between $0.3-3 \mathrm{~W} / \mathrm{cm}^{2}$. However, higher

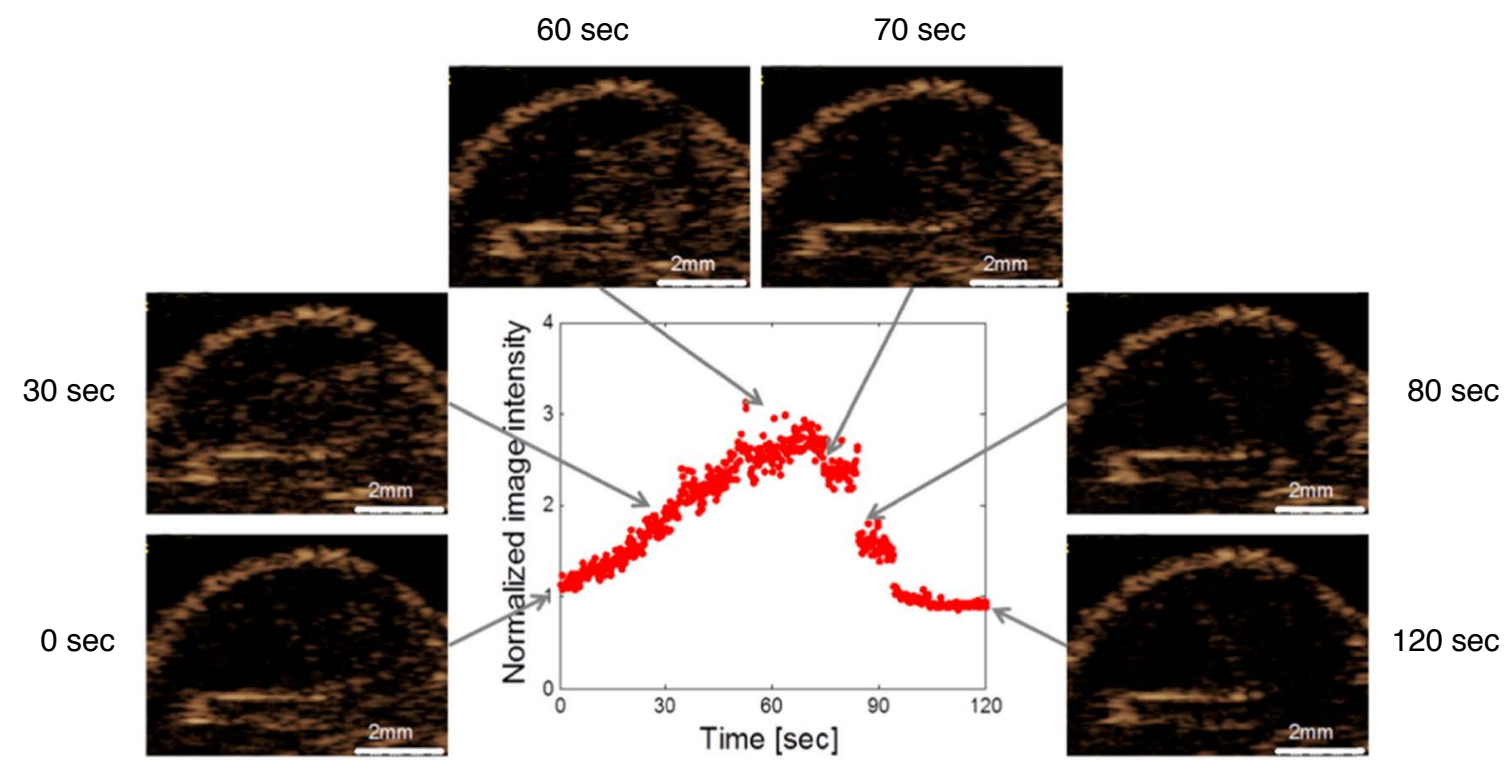

A

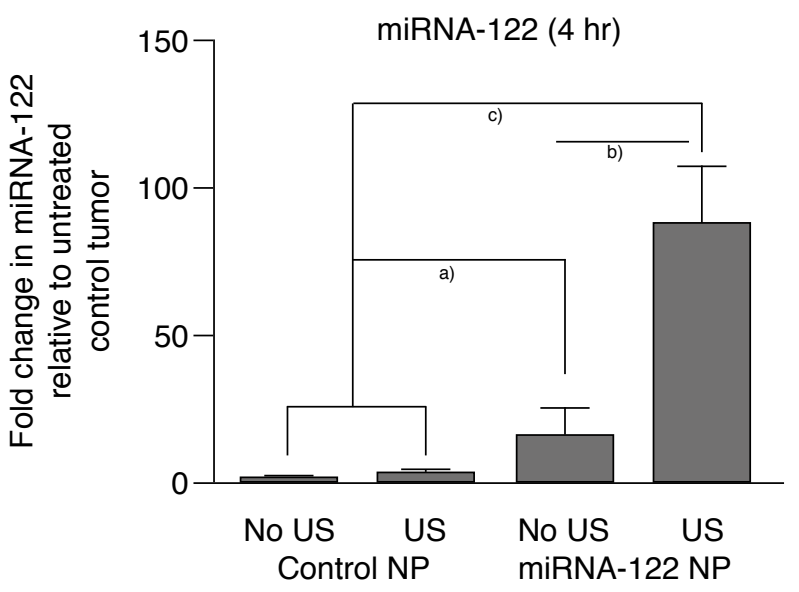

B

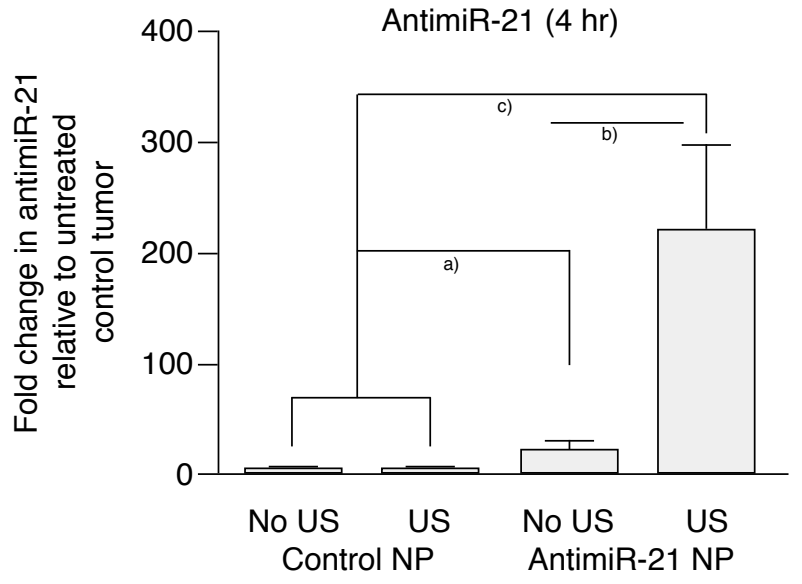

C

Fig. 4. Ultrasound and microbubble (USMB) mediated sonoporation and drug delivery.

A. Representative contrast-enhanced ultrasound (US) images of a subcutaneous cancer xenograft during a 2-minute USMB treatment cycle. Image signal increased as microbubbles entered into the tumor (up to 60 seconds), and then substantially decreased during sonoporation (70-120 seconds), indicating inertial cavitation of the microbubbles. B, C. Quantitative reverse transcription polymerase chain reaction shows that USMB mediated delivery substantially enhances intratumoral delivery of therapeutics such as microRNAs (miRNA) compared to untreated and no-US controls. ${ }^{\mathrm{a}} \mathrm{P}=0.005,{ }^{\mathrm{b}} \mathrm{P}=0.002,{ }^{\mathrm{C}} \mathrm{P}=0.001$, all compared to untreated control tumors. Adapted from Mullick Chowdhury et al. J Control Release 2016;238:272-280, with permission from Elsevier through RightsLink [5] and Wang et al. J Control Release 2015;203:99-108, with permission from Elsevier through RightsLink [22]. 
Table 1. Examples of publications on ultrasound guided drug delivery in various types of cancer

\begin{tabular}{|c|c|c|c|c|c|}
\hline Cancer type & Study & Drug & Model & US parameter & Effect \\
\hline \multirow[t]{15}{*}{ Brain cancer } & Liu et al. [75] & $\mathrm{BCNU}$ & Rat xenograft & Frequency $0.4 \mathrm{MHz}$ & $\begin{array}{l}\text { Drug delivery increased 2-fold } \\
\text { compared to control }\end{array}$ \\
\hline & & & & Pressure $0.62 \mathrm{MPa}$ & Tumor growth suppressed \\
\hline & & & & Pulse length $10 \mathrm{msec}$ & \\
\hline & & & & PRF $1 \mathrm{~Hz}$ & \\
\hline & & & & 1-Day treatment & \\
\hline & Li et al. [76] & $\mathrm{BCNU}$ & Rat xenograft & Frequency $1 \mathrm{MHz}$ & Drug circulation prolonged \\
\hline & & & & Pressure $0.7 \mathrm{MPa}$ & Liver accumulation decreased \\
\hline & & & & Pulse length $10 \mathrm{msec}$ & Tumor growth suppressed \\
\hline & & & & PRF $5 \mathrm{~Hz}$ & \\
\hline & & & & 2-Day treatment & \\
\hline & Treat et al. [77] & Doxorubicin & $\begin{array}{l}\text { Rat subcutaneous } \\
\text { xenograft }\end{array}$ & Frequency $1.7 \mathrm{MHz}$ & Tumor growth suppressed \\
\hline & & & & Pressure $1.2 \mathrm{MPa}$ & \\
\hline & & & & Pulse length $10 \mathrm{msec}$ & \\
\hline & & & & PRF $1 \mathrm{~Hz}$ & \\
\hline & & & & 1-Day treatment & \\
\hline \multirow[t]{21}{*}{$\begin{array}{l}\text { Hepatocellular } \\
\text { carcinoma }\end{array}$} & Kang et al. [78] & Doxorubicin & $\begin{array}{l}\text { Rabbit orthotopic } \\
\text { xenograft }\end{array}$ & Frequency $0.3 \mathrm{MHz}$ & Tumor growth suppressed \\
\hline & & & & Intensity $2 \mathrm{~W} / \mathrm{cm}^{2}$ & Tumor cell apoptosis observed \\
\hline & & & & Pulse length 10 sec on 10 sec off & \\
\hline & & & & 3-Day treatment & \\
\hline & Cochran et al. [79] & Doxorubicin & $\begin{array}{l}\text { Rabbit subcutaneous } \\
\text { xenograft }\end{array}$ & Frequency $12-5 \mathrm{MHz}$ & $\begin{array}{l}\text { Drug delivery increased 7-fold } \\
\text { compared to control }\end{array}$ \\
\hline & & & & Mechanical Index 0.4-0.45 & Tumor growth suppressed \\
\hline & & & & PRF $1,000 \mathrm{~Hz}$ & \\
\hline & & & & 1-Day treatment & \\
\hline & Li et al. [76] & HCPT & $\begin{array}{l}\text { Mice subcutaneous } \\
\text { xenograft }\end{array}$ & Frequency $1 \mathrm{MHz}$ & $\begin{array}{l}\text { Drug delivery increased 5-fold } \\
\text { compared to control }\end{array}$ \\
\hline & & & & Intensity $2 \mathrm{~W} / \mathrm{cm}^{2}$ & Tumor growth suppressed \\
\hline & & & & Pulse length 10 sec on 10 sec off & \\
\hline & & & & 7-Day treatment & \\
\hline & Zhu et al. [80] & Doxorubicin & $\begin{array}{l}\text { Mice subcutaneous } \\
\text { xenograft }\end{array}$ & Frequency $1.2 \mathrm{MHz}$ & Tumor growth suppressed \\
\hline & & & & Pressure $0.5 \mathrm{MPa}$ & Mouse survival improved \\
\hline & & & & Mechanical Index 0.4-0.45 & \\
\hline & Nie et al. [81] & HSV-TK pDNA GCV & $\begin{array}{l}\text { Mice subcutaneous } \\
\text { xenograft }\end{array}$ & Frequency $1 \mathrm{MHz}$ & Tumor growth suppressed \\
\hline & & & & Intensity $2 \mathrm{~W} / \mathrm{cm}^{2}$ & Mouse survival improved \\
\hline & & & & 10-Day treatment & \\
\hline & Zhou et al. [27] & HSV-TK pDNA GCV & $\begin{array}{l}\text { Mice subcutaneous } \\
\text { xenograft }\end{array}$ & Frequency $1 \mathrm{MHz}$ & Tumor growth suppressed \\
\hline & & & & Intensity $2 \mathrm{~W} / \mathrm{cm}^{2}$ & Mouse survival improved \\
\hline & & & & 14-Day treatment & \\
\hline
\end{tabular}


Table 1. Examples of publications on ultrasound guided drug delivery in various types of cancer

\begin{tabular}{|c|c|c|c|c|c|}
\hline Cancer type & Study & Drug & Model & US parameter & Effect \\
\hline & Yu et al. [82] & HSV-TK pDNA & $\begin{array}{l}\text { Mice subcutaneous } \\
\text { xenograft }\end{array}$ & Frequency $1.2 \mathrm{MHz}$ & $\begin{array}{l}\text { Tumor growth suppressed } \\
\text { more with both gene treatment } \\
\text { compared to single treatment }\end{array}$ \\
\hline & & Timp3 pDNA & & Mechanical Index 1.3 & \\
\hline & & & & 4-Day treatment & \\
\hline & $\begin{array}{l}\text { Mullick Chowdhury } \\
\text { et al. [5] }\end{array}$ & miRNA-122 & $\begin{array}{l}\text { Mice subcutaneous } \\
\text { xenograft }\end{array}$ & Frequency $1.1 \mathrm{MHz}$ & $\begin{array}{l}\text { Significant therapeutic effects } \\
\text { observed after single treatment }\end{array}$ \\
\hline & & AntimiR-21 & & Pressure $5.3 \mathrm{MPa}$ & \\
\hline & & Doxorubicin & & PRF $1,000 \mathrm{~Hz}$ & \\
\hline & & & & 1-Day single treatment & \\
\hline \multirow[t]{20}{*}{ Breast cancer } & Sorace et al. [18] & Paclitaxel & $\begin{array}{l}\text { Mice subcutaneous } \\
\text { xenograft }\end{array}$ & Frequency $1 \mathrm{MHz}$ & $\begin{array}{l}\text { Tumor growth suppressed; tumor } \\
\text { cell necrosis observed }\end{array}$ \\
\hline & & & & Mechanical Index 0.1-2 & Tumor cell necrosis observed \\
\hline & & & & Pulse length $1,000 \mathrm{msec}$ & \\
\hline & & & & PRF $5 \mathrm{~Hz}$ & \\
\hline & & & & 6-Day treatment & \\
\hline & Bai et al. [83] & ABCG2-siRNA & $\begin{array}{l}\text { Mice subcutaneous } \\
\text { xenograft }\end{array}$ & Frequency $1 \mathrm{MHz}$ & $\begin{array}{l}\text { Tumor cell could overcome drug } \\
\text { drug resistance and become } \\
\text { resensitized }\end{array}$ \\
\hline & & & & PRF $5 \mathrm{~Hz}$ & \\
\hline & & & & 5-Day treatment & \\
\hline & Yan et al. [57] & Paclitaxel & $\begin{array}{l}\text { Mice subcutaneous } \\
\text { xenograft }\end{array}$ & Frequency $2.25 \mathrm{MHz}$ & $\begin{array}{l}\text { Drug accumulation in tumor was } \\
\text { higher compared to control }\end{array}$ \\
\hline & & & & Pressure $1.9 \mathrm{MPa}$ & Lower nonspecific accumulation \\
\hline & & & & Pulse length $10 \mathrm{msec}$ & \\
\hline & & & & PRF $1 \mathrm{~Hz}$ & \\
\hline & & & & 3-Day treatment & \\
\hline & Zhao et al. [84] & Doxorubicin & $\begin{array}{l}\text { Mice subcutaneous } \\
\text { xenograft }\end{array}$ & Frequency $1 \mathrm{MHz}$ & Tumor growth suppressed \\
\hline & & & & Intensity $0.3 \mathrm{~W} / \mathrm{cm}^{2}$ & \\
\hline & & & & Pulse length $10 \mathrm{sec}$ & \\
\hline & Carlisle et al. [85] & $\begin{array}{l}\text { Oncolytic adenovirus } \\
\text { in polymer }\end{array}$ & $\begin{array}{l}\text { Mice subcutaneous } \\
\text { xenograft }\end{array}$ & Frequency $0.5 \mathrm{MHz}$ & $\begin{array}{l}\text { Circulation half-life of adenovirus } \\
\text { better compared to control }\end{array}$ \\
\hline & & & & Pressure $1.2 \mathrm{MPa}$ & $\begin{array}{l}\text { Enhanced tumor infection } \\
\text { efficiency }\end{array}$ \\
\hline & & & & PRF $0.5 \mathrm{~Hz}$ & \\
\hline & & & & 1-Day treatment & \\
\hline \multirow[t]{6}{*}{$\begin{array}{l}\text { Pancreatic } \\
\text { cancer }\end{array}$} & Tinkov et al. [86] & Doxorubicin & $\begin{array}{l}\text { Mice orthotopic } \\
\text { xenograft }\end{array}$ & Frequency $1.3 \mathrm{MHz}$ & $\begin{array}{l}\text { Drug delivery increased } 12 \text {-fold } \\
\text { compared to control }\end{array}$ \\
\hline & & & & Pressure $1.2 \mathrm{MPa}$ & Tumor growth suppressed \\
\hline & & & & PRF $5 \mathrm{~Hz}$ & \\
\hline & $\begin{array}{l}\text { Kotopoulis et al. } \\
\text { [87] }\end{array}$ & Gemcitabine & $\begin{array}{l}\text { Mice orthotopic } \\
\text { xenograft }\end{array}$ & Frequency $1 \mathrm{MHz}$ & Tumor growth suppressed \\
\hline & & & & Mechanical Index 0.1-2 & \\
\hline & & & & 8-Day treatment & \\
\hline \multirow[t]{3}{*}{ Melanoma } & Sonoda et al. [88] & Bleomycin & Mice eyelid xenograft & Frequency $1 \mathrm{MHz}$ & Tumor growth suppressed \\
\hline & & & & Intensity $1 \mathrm{~W} / \mathrm{cm}^{2}$ & No nonspecific toxicity \\
\hline & & & & 4-Day treatment & \\
\hline
\end{tabular}


intensity ultrasound can be used when the pulse length (pulse cycles/ultrasound frequency) and/or pulse repetition frequency (pulses/sec) are reduced, resulting in low duty cycles (pulse length $\times$ pulse repetition frequency) and, thus, decreased temporal average intensity (duty cyclexultrasound intensity).

\section{Mechanical Index}

The Ml of ultrasound is defined as the peak negative pressure (in $\mathrm{MPa}$ ) divided by the square root of center frequency (in MHz). The
MI is often used as an alternative parameter to ultrasound intensity as both are directly proportional to the applied acoustic pressure. Also, the Ml provides a direct measure of the generated cavitation as higher Ml leads to higher cavitation activity. In order to avoid unwanted thermal effects during therapy, the MI usually ranges between 0.2 and 1.9 [89]. The FDA has set the upper limit of the MI to 1.9 for clinical ultrasound applications to minimize direct tissue damage by ultrasound [89].

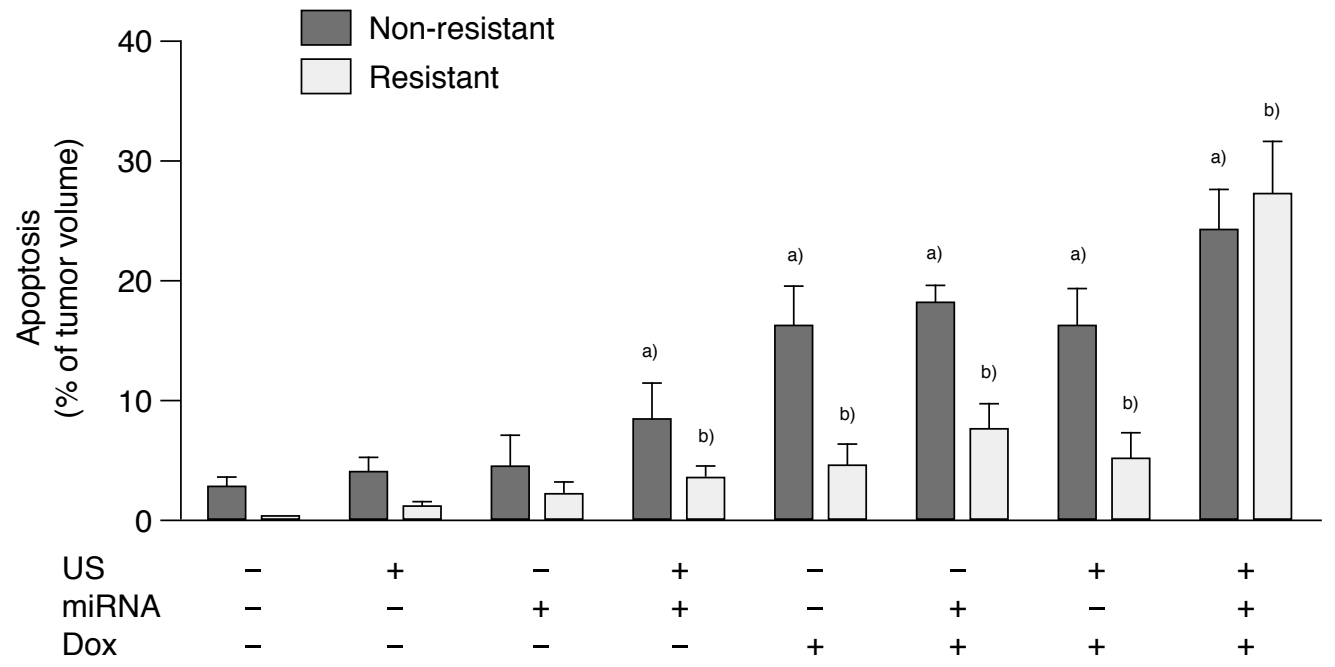

A

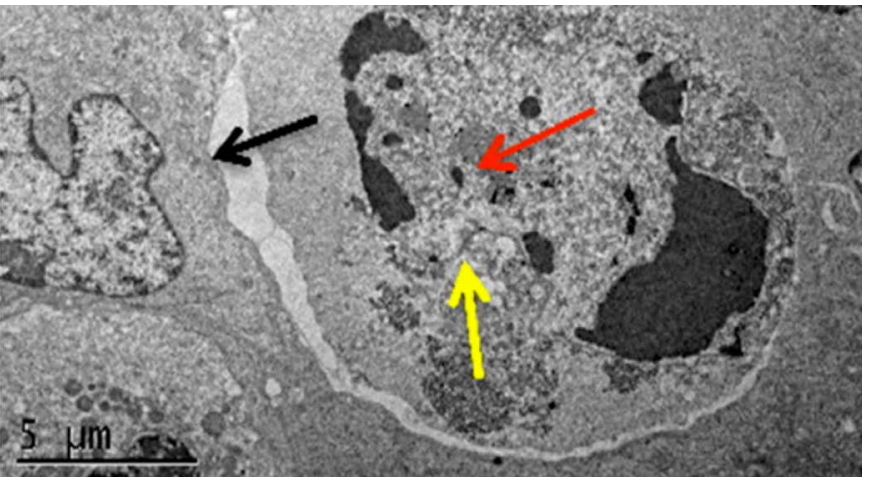

B

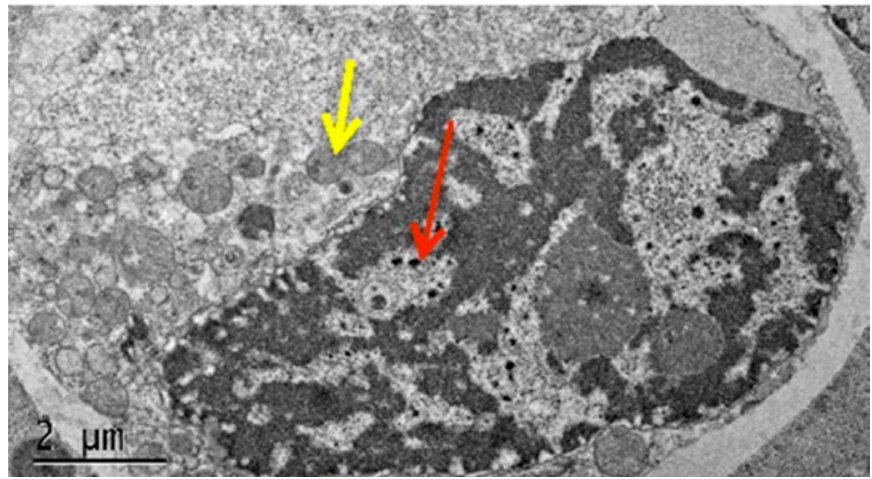

C

Fig. 5. Therapeutic effects of ultrasound and microbubble (USMB) mediated drug delivery.

A. Summary of terminal deoxynucleotidyl transferase dUTP nick end labeling assay data for quantification of apoptosis shows USMB mediated delivery of miRNAs resulted in increased therapeutic effects compared to control conditions in both doxorubicin (DOX)-resistant and non-resistant human hepatocellular carcinoma (HCC) xenografts in mice. US, ultrasound; miRNA, miRNA122+antimiRNA-21. ${ }^{\text {a),b) }} \mathrm{P}<0.05$ compared to untreated control tumors. B, C. Transmission electron microscopy image shows that USMB mediated therapeutic delivery can result in entry of therapeutic miRNA loaded poly lactic-co-glycolic acid nanoparticles into tumor cells ultimately resulting in apoptosis of the cells. Red arrows show internalized nanoparticles, yellow arrows show double layered vacuolar structures in the cytoplasm, and black arrow demonstrates evidence of detachment from surrounding HCC cells, indicating apoptosis. Adapted from Mullick Chowdhury et al. I Control Release 2016;238:272-280, with permission from Elsevier through RightsLink [5]. 

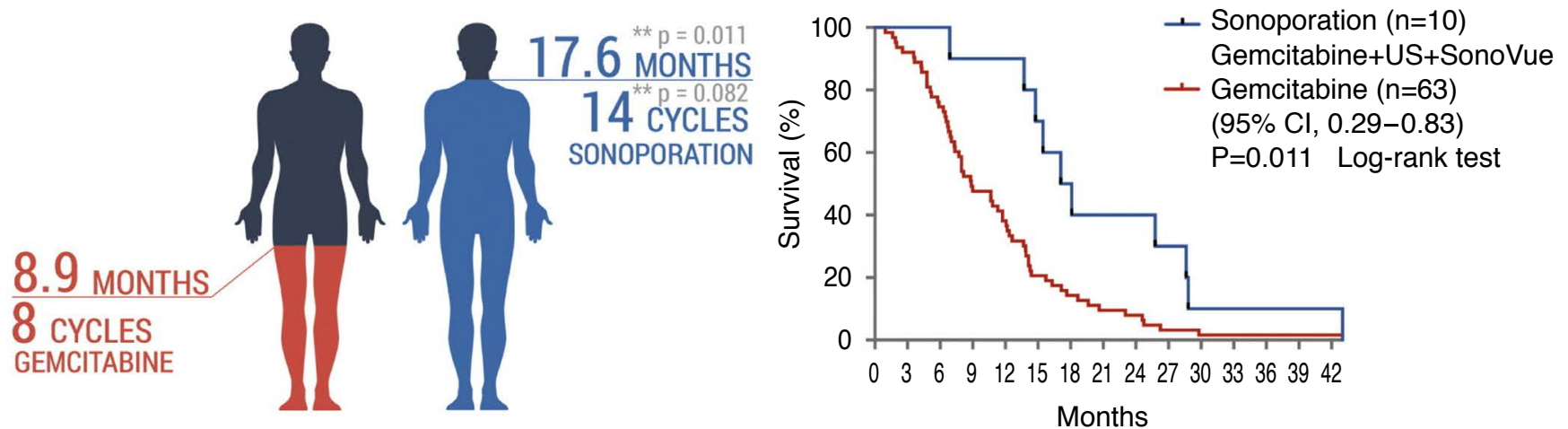

Fig. 6. First clinical ultrasound (US) and microbubble (MB) mediated drug delivery study. Comparison of patients treated with US, MB, and gemcitabine versus gemcitabine alone indicates that survival improved in the combined treatment group compared to treatment with gemcitabine alone. Median survival was found to improve from 8.9 to 17.6 months ( $P=0.011$, log-rank test) with the use of sonoporation. Patients treated with sonoporation also showed a statistically significant increase in number of treatment cycles ( $P=0.082$, unpaired t test) indicating less toxicity to the patients. Cl, confidence interval. Adapted from Dimsevski et al. J Control Release 2016;243:172-181, according to Creative Common license [9].

\section{Treatment Duration}

The treatment duration of USMB mediated drug delivery should be guided by the time taken for the ultrasound to induce inertial or stable cavitation and sonoporation while avoiding unwanted thermal effects. Additionally, the duration of ultrasound application for drug delivery also depends on factors such as the type and location of tissues being treated, the type of microbubbles used, as well as the ultrasound intensity being applied [90]. At high pressures, causing immediate inertial cavitation, multiple or continuous injections of microbubbles, and prolonged treatment times can enhance the efficacy of delivery. However, high pressures can cause unwanted damage to the tissues. Similarly, at lower pressures, the time needed for stable oscillations of microbubbles also needs to be considered for obtaining optimum drug delivery because prolonged treatment times at low pressures can also result in heating effects. Thus, the treatment duration as part of the therapeutic protocol has to be optimized for each treatment indication.

\section{Examples of USMB Mediated Drug Delivery in Cancer}

Several preliminary studies in various different cancer types have shown that USMB mediated drug delivery can be successfully implemented for therapeutic applications (Table 1) $[18,27,57,75-$ 88]. USMB mediated drug delivery has shown direct tumoricidal effects, improved bio-distribution of drugs (effective targeting), and reversal of drug resistance $[12,87]$. Recently, it has been shown that an optimized USMB mediated drug delivery protocol allows successful delivery of significant amounts of PLGA nanoparticles loaded with a combination of two therapeutic miRNAs (miRNA-122 and antimiR-21) into HCC (Fig. 4B, C) [5]. In that study, doxorubicin resistant $\mathrm{HCC}$ could be re-sensitized with a significant therapeutic effect ( 27\% apoptotic cells) after a single round of therapeutic PLGA nanoparticle delivery (Fig. 5) [5]. USMB mediated drug delivery can also serve as an adjuvant treatment to other cancer therapies, as well as a potential approach to cancer vaccination [91,92]. Kotopoulis et al. [10] have recently performed a pilot first clinical study to show that USMB mediated delivery of gemcitabine can significantly improve survival in pancreatic cancer patients compared to patients treated with only gemcitabine (Fig. 6) [9].

\section{Outlook and Future Directions}

Ultrasound parameters for improved drug delivery require considerable optimization, as current ultrasound systems for drug delivery usually employ clinical diagnostic ultrasound systems with a narrow range of tunable ultrasound parameters. Therefore, current research focuses on developing dedicated ultrasound systems that allow fine-tuning of a broad range of tunable ultrasound parameters along with 3D capabilities to allow homogenous of whole tumor volumes.

Also, to further progress USMB mediated drug delivery technology a system is needed that allows monitoring acoustic effects and an estimation of the amount of delivered drugs in the target tissues, ideally in real time during treatment. This is particularly important in the treatment of cancer to overcome challenges of drug delivery associated with tissue heterogeneity of cancer that may result in heterogeneous drug delivery and, thus, incomplete 
treatment and recurrence of cancer. Among other monitoring systems, ultrasound-based monitoring systems are advantageous since they can be directly integrated into the therapeutic ultrasound device. One possible approach to monitor USMB mediated drug delivery measures cavitation emission during treatment. Non-linear microbubble oscillations during treatment generate sub-harmonic and harmonic (stable cavitation) and broadband (inertial cavitation) emissions that can be measured [93]. Unlike active cavitation detection, which is based on transmit of sound waves and detection of its echo, in passive cavitation detection the ultrasound detector passively listens to cavitation signals without transmitting sound waves. This passive detection of microbubble cavitation can be potentially employed as a non-invasive biomarker for monitoring drug delivery efficacy if the amount of drug delivered at a particular treatment site can be correlated with the magnitude of passive cavitation. This cavitation dose could be used as a universal unit for measuring USMB mediated drug delivery [94]. Such a universal unit is critically needed in the field of USMB mediated drug delivery since different scientists have used different ultrasound parameters, animal models and microbubble concentrations in various studies, which makes comparison of results challenging. Recently, significant efforts have been made towards using passive cavitation detection as a potential readout of treatment effects $[4,22]$. However, so far those studies have been exclusively based on single element transducers for cavitation detection and, therefore, lacked spatial information of cavitation [22] because in this setting cavitation signals measured with single element detectors represent cavitation intensity averaged over the entire cavitation volume. More recently, passive cavitation mapping capable of both quantifying and spatial mapping of cavitation has been proposed $[95,96]$ by using multielement array transducers instead of single element transducers. In principle, passive cavitation mapping can be used to monitor drug delivery profiles over target tumors. However, passive cavitation mapping algorithms developed so far have limitations in obtaining spatial information due to poor axial mapping resolution. Thus, more developments are needed to quantify and spatially map passive cavitation for monitoring USMB drug delivery.

\section{Conclusion}

USMB mediated drug delivery is an emerging field for improved cancer therapy and several research groups are working towards further developing this technology. This has resulted in significant advancement of the field in recent years and a first pilot clinical trial in patients with advanced stage pancreatic cancer has shown clinical feasibility and safety of this approach [10]. Further technical developments along with better understanding of the underlying mechanisms of improved drug delivery through USMB will help translate this therapeutic strategy into the clinic.

ORCID: Sayan Mullick Chowdhury: http://orcid.org/0000-0002-0502-7531; Taehwa Lee: http://orcid.org/0000-0001-6813-7669; Jürgen K. Willmann: http://orcid. org/0000-0002-9517-4657

\section{Conflict of Interest}

No potential conflict of interest relevant to this article was reported.

\section{Acknowledgments}

Supported by the NIH grants R01 CA155289 (JKW), R01 DK092509 (JKW), R21 EB022298 (JKW), and 2T32 CA118681-11A1 training grant (SMC).

\section{References}

1. Shapiro G, Wong AW, Bez M, Yang F, Tam S, Even L, et al. Multiparameter evaluation of in vivo gene delivery using ultrasound-guided, microbubble-enhanced sonoporation. J Control Release 2016;223:157-164.

2. Helfield B, Chen X, Watkins SC, Villanueva FS. Biophysical insight into mechanisms of sonoporation. Proc Natl Acad Sci U S A 2016;113:9983-9988.

3. Bouakaz A, Zeghimi A, Doinikov AA. Sonoporation: concept and mechanisms. In: Escoffre JM, Bouakaz A, eds. Therapeutic ultrasound. Berlin: Springer, 2016;175-189.

4. Tzu-Yin W, Wilson KE, Machtaler S, Willmann JK. Ultrasound and microbubble guided drug delivery: mechanistic understanding and clinical implications. Curr Pharm Biotechnol 2013;14:743-752.

5. Mullick Chowdhury S, Wang TY, Bachawal S, Devulapally R, Choe JW, Abou Elkacem L, et al. Ultrasound-guided therapeutic modulation of hepatocellular carcinoma using complementary microRNAs. J Control Release 2016:238:272-280.

6. Delalande A, Kotopoulis S, Postema M, Midoux P, Pichon C. Sonoporation: mechanistic insights and ongoing challenges for gene transfer. Gene 2013;525:191-199.

7. Lentacker I, De Smedt SC, Sanders NN. Drug loaded microbubble design for ultrasound triggered delivery. Soft Matter 2009;5:2161 2170.

8. Chen $\mathrm{H}$, Hwang $\mathrm{JH}$. Ultrasound-targeted microbubble destruction for chemotherapeutic drug delivery to solid tumors. J Ther Ultrasound 2013;1:10

9. Dimcevski G, Kotopoulis S, Bjanes T, Hoem D, Schjott J, Gjertsen BT, et al. A human clinical trial using ultrasound and microbubbles to enhance gemcitabine treatment of inoperable pancreatic cancer. Control Release 2016;243:172-181.

10. Kotopoulis S, Dimcevski G, Gilja OH, Hoem D, Postema M. Treatment of human pancreatic cancer using combined ultrasound 
microbubbles, and gemcitabine: a clinical case study. Med Phys 2013;40:072902.

11. Carson AR, McTiernan CF, Lavery L, Grata M, Leng X, Wang J, et al. Ultrasound-targeted microbubble destruction to deliver siRNA cancer therapy. Cancer Res 2012;72:6191-6199.

12. Kiessling F, Fokong S, Koczera P, Lederle W, Lammers T. Ultrasound microbubbles for molecular diagnosis, therapy, and theranostics. J Nucl Med 2012;53:345-348.

13. Tsutsui JM, Xie F, Porter RT. The use of microbubbles to target drug delivery. Cardiovasc Ultrasound 2004;2:23.

14. Huang SL. Liposomes in ultrasonic drug and gene delivery. Adv Drug Deliv Rev 2008;60:1167-1176.

15. Schoellhammer CM, Schroeder A, Maa R, Lauwers GY, Swiston A, Zervas $\mathrm{M}$, et al. Ultrasound-mediated gastrointestinal drug delivery. Sci Transl Med 2015;7:310ra168.

16. Tang $H$, Wang CC, Blankschtein D, Langer $R$. An investigation of the role of cavitation in low-frequency ultrasound-mediated transdermal drug transport. Pharm Res 2002;19:1160-1169.

17. Simonin JP. On the mechanisms of in vitro and in vivo phonophoresis. J Control Release 1995;33:125-141.

18. Sorace AG, Warram JM, Umphrey H, Hoyt K. Microbubble-mediated ultrasonic techniques for improved chemotherapeutic delivery in cancer. J Drug Target 2012;20:43-54.

19. Unger EC, Hersh E, Vannan M, Matsunaga TO, McCreery T. Local drug and gene delivery through microbubbles. Prog Cardiovasc Dis 2001;44:45-54.

20. Bettinger T, Tranquart F. Design of microbubbles for gene/drug delivery. In: Escoffre JM, Bouakaz A, eds. Therapeutic ultrasound. Berlin: Springer, 2016;191-204.

21. Chomas JE, Dayton PA, May D, Allen J, Klibanov A, Ferrara K. Optical observation of contrast agent destruction. Appl Phys Lett 2000;77:1056-1058.

22. Wang TY, Choe JW, Pu K, Devulapally R, Bachawal S, Machtaler S, et al. Ultrasound-guided delivery of microRNA loaded nanoparticles into cancer. J Control Release 2015;203:99-108.

23. Wang XL, Zhao XY, Li S, Jia CJ, Jiang L, Shi TM, et al. A novel plasmid and SonoVue formulation plus ultrasound sonication for effective gene delivery in nude mice. Life Sci 2013;93:536-542.

24. Rapoport N. Drug-loaded perfluorocarbon nanodroplets for ultrasound-mediated drug delivery. In: Escoffre JM, Bouakaz A, eds. Therapeutic ultrasound. Berlin: Springer, 2016;221-241.

25. Lee JY, Carugo D, Crake C, Owen J, de Saint Victor M, Seth A, et al. Nanoparticle-loaded protein-polymer nanodroplets for improved stability and conversion efficiency in ultrasound imaging and drug delivery. Adv Mater 2015;27:5484-5492.

26. Boissenot T, Bordat A, Fattal E, Tsapis N. Ultrasound-triggered drug delivery for cancer treatment using drug delivery systems: from theoretical considerations to practical applications. J Control Release 2016;241:144-163.
27. Zhou S, Li S, Liu Z, Tang Y, Wang Z, Gong J, et al. Ultrasoundtargeted microbubble destruction mediated herpes simplex virusthymidine kinase gene treats hepatoma in mice. J Exp Clin Cancer Res 2010;29:170.

28. Wang DS, Panje C, Pysz MA, Paulmurugan R, Rosenberg J, Gambhir SS, et al. Cationic versus neutral microbubbles for ultrasoundmediated gene delivery in cancer. Radiology 2012;264:721-732.

29. Borden MA, Caskey CF, Little E, Gillies RJ, Ferrara KW. DNA and polylysine adsorption and multilayer construction onto cationic lipid-coated microbubbles. Langmuir 2007;23:9401-9408.

30. Hernot S, Klibanov AL. Microbubbles in ultrasound-triggered drug and gene delivery. Adv Drug Deliv Rev 2008;60:1153-1166.

31. Unger EC, McCreery TP, Sweitzer RH, Caldwell VE, Wu Y. Acoustically active lipospheres containing paclitaxel: a new therapeutic ultrasound contrast agent. Invest Radiol 1998;33:886-892.

32. Tartis MS, McCallan J, Lum AF, LaBell R, Stieger SM, Matsunaga TO, et al. Therapeutic effects of paclitaxel-containing ultrasound contrast agents. Ultrasound Med Biol 2006;32:1771-1780.

33. Panje CM, Wang DS, Pysz MA, Paulmurugan $R$, Ren $Y$, Tranquart $F$, et al. Ultrasound-mediated gene delivery with cationic versus neutral microbubbles: effect of DNA and microbubble dose on in vivo transfection efficiency. Theranostics 2012;2:1078-1091.

34. Bekeredjian R, Chen S, Frenkel PA, Grayburn PA, Shohet RV. Ultrasound-targeted microbubble destruction can repeatedly direct highly specific plasmid expression to the heart. Circulation 2003;108:1022-1026.

35. Anderson $C R$, Hu $X$, Zhang $H$, Tlaxca J, Decleves AE, Houghtaling $R$, et al. Ultrasound molecular imaging of tumor angiogenesis with an integrin targeted microbubble contrast agent. Invest Radiol 2011:46:215-224.

36. Abou-Elkacem L, Bachawal SV, Willmann JK. Ultrasound molecular imaging: moving toward clinical translation. Eur J Radiol 2015;84:1685-1693.

37. Bachawal SV, Jensen KC, Lutz AM, Gambhir SS, Tranquart F, Tian L, et al. Earlier detection of breast cancer with ultrasound molecular imaging in a transgenic mouse model. Cancer Res 2013;73:16891698.

38. Deshpande N, Needles A, Willmann JK. Molecular ultrasound imaging: current status and future directions. Clin Radiol 2010;65:567-581.

39. Pysz MA, Gambhir SS, Willmann JK. Molecular imaging: current status and emerging strategies. Clin Radiol 2010;65:500-516.

40. Willmann JK, van Bruggen N, Dinkelborg LM, Gambhir SS. Molecular imaging in drug development. Nat Rev Drug Discov 2008;7:591-607.

41. Kircher MF, Willmann JK. Molecular body imaging: MR imaging, CT, and US. Part I. principles. Radiology 2012;263:633-643.

42. Wilson KE, Wang TY, Willmann JK. Acoustic and photoacoustic molecular imaging of cancer. J Nucl Med 2013;54:1851-1854. 
43. Pysz MA, Willmann JK. Targeted contrast-enhanced ultrasound: an emerging technology in abdominal and pelvic imaging. Gastroenterology 2011;140:785-790.

44. Foygel K, Wang H, Machtaler S, Lutz AM, Chen R, Pysz M, et al. Detection of pancreatic ductal adenocarcinoma in mice by ultrasound imaging of thymocyte differentiation antigen 1. Gastroenterology 2013;145:885-894.

45. Willmann JK, Kimura RH, Deshpande N, Lutz AM, Cochran JR, Gambhir SS. Targeted contrast-enhanced ultrasound imaging of tumor angiogenesis with contrast microbubbles conjugated to integrin-binding knottin peptides. J Nucl Med 2010;51:433-440.

46. Kircher MF, Willmann JK. Molecular body imaging: MR imaging, CT, and US. Part II. Applications. Radiology 2012;264:349-368.

47. Unger EC, Porter T, Culp W, Labell R, Matsunaga T, Zutshi R. Therapeutic applications of lipid-coated microbubbles. Adv Drug Deliv Rev 2004;56:1291-1314.

48. Duan L, Yang F, He W, Song L, Qiu F, Xu N, et al. A multi-gradient targeting drug delivery system based on RGD-L-TRAlL-labeled magnetic microbubbles for cancer theranostics. Adv Funct Mater 2016;26:8313-8324.

49. Panje CM, Wang DS, Willmann JK. Ultrasound and microbubblemediated gene delivery in cancer: progress and perspectives. Invest Radiol 2013;48:755-769.

50. Pysz MA, Foygel K, Rosenberg J, Gambhir SS, Schneider M, Willmann JK. Antiangiogenic cancer therapy: monitoring with molecular US and a clinically translatable contrast agent (BR55). Radiology 2010;256:519-527.

51. Deshpande N, Ren Y, Foygel K, Rosenberg J, Willmann JK. Tumor angiogenic marker expression levels during tumor growth: longitudinal assessment with molecularly targeted microbubbles and US imaging. Radiology 2011;258:804-811.

52. Willmann JK, Bonomo L, Carla Testa A, Rinaldi P, Rindi G, Valluru $\mathrm{KS}$, et al. Ultrasound molecular imaging with BR55 in patients with breast and ovarian lesions: first-in-human results. J Clin Oncol 2017 Mar 14 [Epub]. https://doi.org/10.1200/JC0.2016.70.8594.

53. Morch Y, Hansen R, Berg S, Aslund AK, Glomm WR, Eggen S, et al. Nanoparticle-stabilized microbubbles for multimodal imaging and drug delivery. Contrast Media Mol Imaging 2015;10:356-366.

54. Lv Y, Hao L, Hu W, Ran Y, Bai Y, Zhang L. Novel multifunctional pHsensitive nanoparticles loaded into microbubbles as drug delivery vehicles for enhanced tumor targeting. Sci Rep 2016;6:29321.

55. Liu HL, Fan $C H$, Ting $C Y$, Yeh CK. Combining microbubbles and ultrasound for drug delivery to brain tumors: current progress and overview. Theranostics 2014;4:432-444.

56. Paris JL, Cabanas MV, Manzano M, Vallet-Regi M. Polymer-grafted mesoporous silica nanoparticles as ultrasound-responsive drug carriers. ACS Nano 2015;9:11023-11033.

57. Yan F, Li L, Deng Z, Jin Q, Chen J, Yang W, et al. Paclitaxel-liposomemicrobubble complexes as ultrasound-triggered therapeutic drug delivery carriers. J Control Release 2013;166:246-255.

58. Sirsi SR, Borden MA. State-of-the-art materials for ultrasoundtriggered drug delivery. Adv Drug Deliv Rev 2014;72:3-14.

59. Devulapally R, Sekar NM, Sekar TV, Foygel K, Massoud TF, Willmann $\mathrm{JK}$, et al. Polymer nanoparticles mediated codelivery of antimiR-10b and antimiR-21 for achieving triple negative breast cancer therapy. ACS Nano 2015;9:2290-2302.

60. Devulapally R, Foygel K, Sekar TV, Willmann JK, Paulmurugan R. Gemcitabine and antisense-microRNA co-encapsulated PLGA-PEG polymer nanoparticles for hepatocellular carcinoma therapy. ACS Appl Mater Interfaces 2016;8:33412-33422.

61. Husseini GA, Diaz de la Rosa MA, Richardson ES, Christensen DA, Pitt WG. The role of cavitation in acoustically activated drug delivery. J Control Release 2005;107:253-261.

62. Mukundakrishnan K, Ayyaswamy PS, Eckmann DM. Bubble motion in a blood vessel: shear stress induced endothelial cell injury. J Biomech Eng 2009;131:074516.

63. Caskey CF, Stieger SM, Qin S, Dayton PA, Ferrara KW. Direct observations of ultrasound microbubble contrast agent interaction with the microvessel wall. J Acoust Soc Am 2007;122:1191-1200.

64. Quinto-Su PA, Ohl CD. Interaction between two laser-induced cavitation bubbles in a quasi-two-dimensional geometry. J Fluid Mech 2009;633:425-435.

65. Blake JR, Gibson DC. Cavitation bubbles near boundaries. Ann Rev Fluid Mech 1987;19:99-123.

66. Lauterborn W, Ohl CD. Cavitation bubble dynamics. Ultrason Sonochem 1997;4:65-75.

67. Arora $\mathrm{M}, \mathrm{Ohl} C \mathrm{CD}$, Lohse $\mathrm{D}$. Effect of nuclei concentration on cavitation cluster dynamics. J Acoust Soc Am 2007;121:3432-3436.

68. Tun MT, Pai RK, Kwok S, Dong A, Gupta A, Visser BC, et al. Diagnostic accuracy of cyst fluid amphiregulin in pancreatic cysts. BMC Gastroenterol 2012;12:15.

69. Unnikrishnan S, Klibanov AL. Microbubbles as ultrasound contrast agents for molecular imaging: preparation and application. AJR Am J Roentgenol 2012;199:292-299.

70. Apfel RE, Holland CK. Gauging the likelihood of cavitation from short-pulse, low-duty cycle diagnostic ultrasound. Ultrasound Med Biol 1991;17:179-185.

71. Ferrara K, Pollard R, Borden M. Ultrasound microbubble contrast agents: fundamentals and application to gene and drug delivery. Annu Rev Biomed Eng 2007:9:415-447.

72. de Jong N, Emmer M, van Wamel A, Versluis M. Ultrasonic characterization of ultrasound contrast agents. Med Biol Eng Comput 2009;47:861-873.

73. Guan L, Xu G. Damage effect of high-intensity focused ultrasound on breast cancer tissues and their vascularities. World J Surg Oncol 2016;14:153.

74. Azagury A, Amar-Lewis E, Yudilevitch Y, Isaacson C, Laster B, Kost J. Ultrasound effect on dancerous versus non-cancerous cells. 
Ultrasound Med Biol 2016;42:1560-1567.

75. Liu HL, Hua MY, Chen PY, Chu PC, Pan CH, Yang HW, et al. Bloodbrain barrier disruption with focused ultrasound enhances delivery of chemotherapeutic drugs for glioblastoma treatment. Radiology 2010;255:415-425.

76. Li P, Zheng Y, Ran H, Tan J, Lin Y, Zhang Q, et al. Ultrasound triggered drug release from 10-hydroxycamptothecin-loaded phospholipid microbubbles for targeted tumor therapy in mice. J Control Release 2012;162:349-354.

77. Treat LH, McDannold N, Zhang Y, Vykhodtseva N, Hynynen K. Improved anti-tumor effect of liposomal doxorubicin after targeted blood-brain barrier disruption by MRI-guided focused ultrasound in rat glioma. Ultrasound Med Biol 2012;38:1716-1725.

78. Kang J, Wu X, Wang Z, Ran H, Xu C, Wu J, et al. Antitumor effect of docetaxel-loaded lipid microbubbles combined with ultrasoundtargeted microbubble activation on VX2 rabbit liver tumors. J Ultrasound Med 2010;29:61-70.

79. Cochran MC, Eisenbrey JR, Soulen MC, Schultz SM, Ouma RO, White $S B$, et al. Disposition of ultrasound sensitive polymeric drug carrier in a rat hepatocellular carcinoma model. Acad Radiol 2011;18:1341-1348.

80. Zhu F, Jiang Y, Luo F, Li P. Effectiveness of localized ultrasoundtargeted microbubble destruction with doxorubicin liposomes in H22 mouse hepatocellular carcinoma model. J Drug Target 2015;23:323-334.

81. Nie F, Xu HX, Lu MD, Wang Y, Tang Q. Anti-angiogenic gene therapy for hepatocellular carcinoma mediated by microbubble-enhanced ultrasound exposure: an in vivo experimental study. J Drug Target 2008;16:389-395.

82. Yu BF, Wu J, Zhang Y, Sung HW, Xie J, Li RK. Ultrasound-targeted HSVtk and Timp3 gene delivery for synergistically enhanced antitumor effects in hepatoma. Cancer Gene Ther 2013;20:290297.

83. Bai $M$, Shen $M$, Teng $Y$, Sun $Y$, Li F, Zhang $X$, et al. Enhanced therapeutic effect of Adriamycin on multidrug resistant breast cancer by the ABCG2-siRNA loaded polymeric nanoparticles assisted with ultrasound. Oncotarget 2015;6:43779-43790.

84. Zhao YZ, Dai DD, Lu CT, Lv HF, Zhang Y, Li X, et al. Using acoustic cavitation to enhance chemotherapy of DOX liposomes: experiment in vitro and in vivo. Drug Dev Ind Pharm 2012;38:1090-1098.

85. Carlisle R, Choi J, Bazan-Peregrino M, Laga R, Subr V, Kostka L, et al. Enhanced tumor uptake and penetration of virotherapy using polymer stealthing and focused ultrasound. J Natl Cancer Inst 2013;105:1701-1710.

86. Tinkov S, Coester C, Serba S, Geis NA, Katus HA, Winter G, et al. New doxorubicin-loaded phospholipid microbubbles for targeted tumor therapy: in-vivo characterization. J Control Release 2010; 148:368-372.

87. Kotopoulis S, Delalande A, Popa M, Mamaeva V, Dimcevski G, Gilja $\mathrm{OH}$, et al. Sonoporation-enhanced chemotherapy significantly reduces primary tumour burden in an orthotopic pancreatic cancer xenograft. Mol Imaging Biol 2014;16:53-62.

88. Sonoda S, Tachibana K, Uchino E, Yamashita T, Sakoda K, Sonoda $\mathrm{KH}$, et al. Inhibition of melanoma by ultrasound-microbubble-aided drug delivery suggests membrane permeabilization. Cancer Biol Ther 2007;6:1276-1283.

89. Barnett SB, Ter Haar GR, Ziskin MC, Rott HD, Duck FA, Maeda $K$. International recommendations and guidelines for the safe use of diagnostic ultrasound in medicine. Ultrasound Med Biol 2000;26:355-366.

90. Mitragotri S. Healing sound: the use of ultrasound in drug delivery and other therapeutic applications. Nat Rev Drug Discov 2005;4:255-260.

91. Escoffre JM, Deckers R, Bos C, Moonen C. Bubble-assisted ultrasound: application in immunotherapy and vaccination. In: Escoffre JM, Bouakaz A, eds. Therapeutic ultrasound. Berlin: Springer, 2016;243-261.

92. Kondo T, Yoshida T, Ogawa R, Hassan MA, Furusawa Y, Zhao QL, et al. Low-intensity ultrasound adjuvant therapy: enhancement of doxorubicin-induced cytotoxicity and the acoustic mechanisms involved. J Med Ultrason (2001) 2009;36:61.

93. Salgaonkar VA, Datta S, Holland CK, Mast TD. Passive cavitation imaging with ultrasound arrays. J Acoust Soc Am 2009;126:30713083.

94. Zhou Y. Principles and applications of therapeutic ultrasound in healthcare. Boca Raton, FL: CRC Press, 2015.

95. Coviello C, Kozick R, Choi J, Gyongy M, Jensen C, Smith PP, et al. Passive acoustic mapping utilizing optimal beamforming in ultrasound therapy monitoring. J Acoust Soc Am 2015;137:25732585.

96. Vignon F, Shi WT, Powers JE, Everbach EC, Liu J, Gao S, et al. Microbubble cavitation imaging. IEEE Trans Ultrason Ferroelectr Freq Control 2013;60:661-670. 